\title{
Role of chemical admixtures in improving wet-mix shotcrete performance for ground support
}

\author{
E Yurdakul GCP Applied Technologies, USA \\ N Jackson GCP Applied Technologies, Australia \\ KA Rieder GCP Applied Technologies, USA
}

\begin{abstract}
This paper presents the results of laboratory and field experiments conducted for a major ground support operation to assess the performance of wet-mix shotcrete incorporating various chemical admixtures. The project had an alkali-silica reaction (ASR) risk due to the aggregates available in the region being reactive. Therefore, a customised mix design was prepared and specialty chemical admixtures formulated with the latest available technologies were selected to mitigate the ASR while meeting the project specifications. The performance of the proposed system, which contained $25 \%$ fly ash and $0.8 \%$ of pozzolanic-based rheology control agent, was compared with the reference mix containing $8 \%$ silica fume as well as the target performance limits of the project. Test results showed that, when compared to the reference mix, the proposed system improved the shotcrete performance by reducing the ASR potential, increasing early-age strength, enhancing sprayability by increasing the stickiness and cohesiveness, and meeting later-age strength, toughness, and durability requirements.
\end{abstract}

Keywords: fly ash, wet-mix shotcrete, ground support

\section{Introduction}

Wet-mix shotcrete is widely used in ground support applications to support permanent openings such as ramps, haulages, shaft stations, and crusher chambers. The quality of such applications is affected by the performance of shotcrete. Therefore, the following properties are often tested to evaluate the performance of shotcrete mixes:

- Slump or slump flow, which indicates the pumpability characteristics.

- Rebound, which is affected by the cohesiveness, stickiness, and viscosity of the mix.

- Air content.

- Early-age strength development rate, which indicates the time requiring for re-entry.

- Later-age strength.

- Permeability, which indicates the service life (often assessed by the results of boiled absorption and volume of permeable voids testing).

- Adhesion strength between shotcrete and rock, which indicates the bonding ability.

- Flexural toughness.

Since silica fume improves many of these properties, the use of silica fume as a supplementary cementitious material (SCM) is quite common in the manufacture of shotcrete. The project owner was also initially interested in using silica fume, however, due to the following reasons, TYTRO ${ }^{\circledR}$ RC $^{430}$, pozzolanic-based rheology control agent, was selected as a full replacement to silica fume:

- Silica fume is powder whereas pozzolanic-based rheology control agent is liquid, which makes it easy to handle. 
- Silica fume is a by-product incorporating impurities causing variations in shotcrete performance while pozzolanic-based rheology control agent is an engineered product that has consistent quality.

- Pozzolanic-based rheology control agent provides greater cohesion to the mix, therefore, while also improving the sprayability and pumpability, it reduces rebound and increases maximum build-up thickness.

- Pozzolanic-based rheology control agent has higher pozzolanic activity than silica fume, which accelerates the hydration process and reduces the time of setting and increases early age strength while having no detrimental impact on the long-term performance (Bergna \& Roberts 2006; Ovstaas et al. 2015; Yurdakul \& Rieder 2015).

- Pozzolanic-based rheology control agent requires only $1 / 10$ th of the silica fume dosage to provide equivalent performance, which makes it a more economical and sustainable solution.

\section{$2 \quad$ Methodology}

\subsection{Aggregate gradation}

Combined aggregate system with a nominal maximum size of $10 \mathrm{~mm}$ was used. Sand-to-total aggregate ratio was selected as $70 \%$. The gradation was within the limits of the project specification as shown in Table 1.

Table 1 Combined aggregate gradation

\begin{tabular}{|lcc|}
\hline $\begin{array}{l}\text { Sieve size } \\
(\mathbf{m m})\end{array}$ & $\begin{array}{c}\text { Percent passing } \\
\text { (project specification) }\end{array}$ & $\begin{array}{c}\text { Percent passing } \\
\text { (combined aggregates } \\
\text { used in the project) }\end{array}$ \\
\hline 10 & $90-100$ & 98 \\
\hline 4.75 & $70-85$ & 72 \\
\hline 2.40 & $50-70$ & 59 \\
\hline 1.20 & $35-55$ & 48 \\
\hline 0.60 & $20-35$ & 35 \\
\hline 0.30 & $8-20$ & 18 \\
\hline 0.15 & $2-10$ & 4 \\
\hline
\end{tabular}

\subsection{Mix design}

Aggregates used in the project region were reported to be reactive, which became a major concern for the project engineers because amorphous or poorly crystallised silica within reactive aggregates and ions from the pore solution of concrete (hydroxyls, alkalis, and calcium ions) result in alkali-silica reaction (ASR) (Garcia-Diaz et al. 2006; Glasser \& Kataoka 1981). Considering these detrimental impacts of ASR (often referred as the 'cancer of concrete') on reducing concrete serviceability and longevity through cracking, displacements, deformations, and performance reduction (Poyet et al. 2007), mix design was selected carefully to mitigate the ASR, as shown in Table 2. 
Table 2 Mix design

\begin{tabular}{|c|c|c|}
\hline Mix components & Reference mix & Proposed mix \\
\hline $\begin{array}{l}\text { ASTM C150/C150M Type I/II ordinary Portland } \\
\text { cement, } \mathrm{kg} / \mathrm{m}^{3}\end{array}$ & 425 & 319 \\
\hline Silica fume, $\mathrm{kg} / \mathrm{m}^{3}$ & 35 & 0 \\
\hline Fly ash, $\mathrm{kg} / \mathrm{m}^{3}$ & 0 & 106 \\
\hline Total binder content, $\mathrm{kg} / \mathrm{m}^{3}$ & 460 & 425 \\
\hline Water-to-cementitious materials ratio $(\mathrm{w} / \mathrm{cm})$ & 0.41 & 0.41 \\
\hline Sand-to-total aggregate ratio, $\%$ & 70 & 70 \\
\hline High-range water-reducing admixture, $\mathrm{L} / \mathrm{m}^{3}$ & 2.0 & TYTRO $^{\circledR}$ WR 1571.9 \\
\hline Air-entraining admixture, $\mathrm{L} / \mathrm{m}^{3}$ & 0.1 & TYTRO $^{\circledR}$ AE 2500.1 \\
\hline Pozzolanic-based rheology control agent, $\mathrm{L} / \mathrm{m}^{3}$ & 0 & TYTRO $^{\circledR}$ RC 4303.0 \\
\hline $\begin{array}{l}\text { Alkali-free set accelerator, } \% \text { of total } \\
\text { cementitious materials content }\end{array}$ & 6 & TYTRO $^{\circledR}$ SA 5306 \\
\hline Macro-synthetic fibres, $\mathrm{kg} / \mathrm{m}^{3}$ & 6 & STRUX ${ }^{\oplus} 90 / 406$ \\
\hline
\end{tabular}

\section{Results and discussion}

Assessment was made in two phases to fully evaluate the performance of the proposed mix:

- Phase 1: Pre-trials under laboratory conditions to develop a suitable mix design.

- Phase 2: Field trials to confirm the performance of the proposed mix at actual jobsite.

\subsection{Phase 1 - pre-trials under laboratory conditions}

\subsubsection{Alkali-silica reaction}

Accelerated mortar-bar testing (ASTM International 2013) was done to confirm the reactivity of the aggregates and determine which SCM would be a suitable option to mitigate ASR. As it is well published in the literature (Chiu \& Olek 2014; Degirmenci et al. 2011), mixes that expand more than $0.10 \%$ at 16 days after casting are indicative of potentially deleterious expansion. Based on Figure 1 , it is confirmed that aggregates are highly reactive as the mix containing Portland cement only had significantly higher expansion than the limit. While incorporating both SCM types helped reducing the ASR risk, mix containing $25 \%$ fly ash combined with $0.8 \%$ pozzolanic-based rheology control agent provided the lowest expansion. 


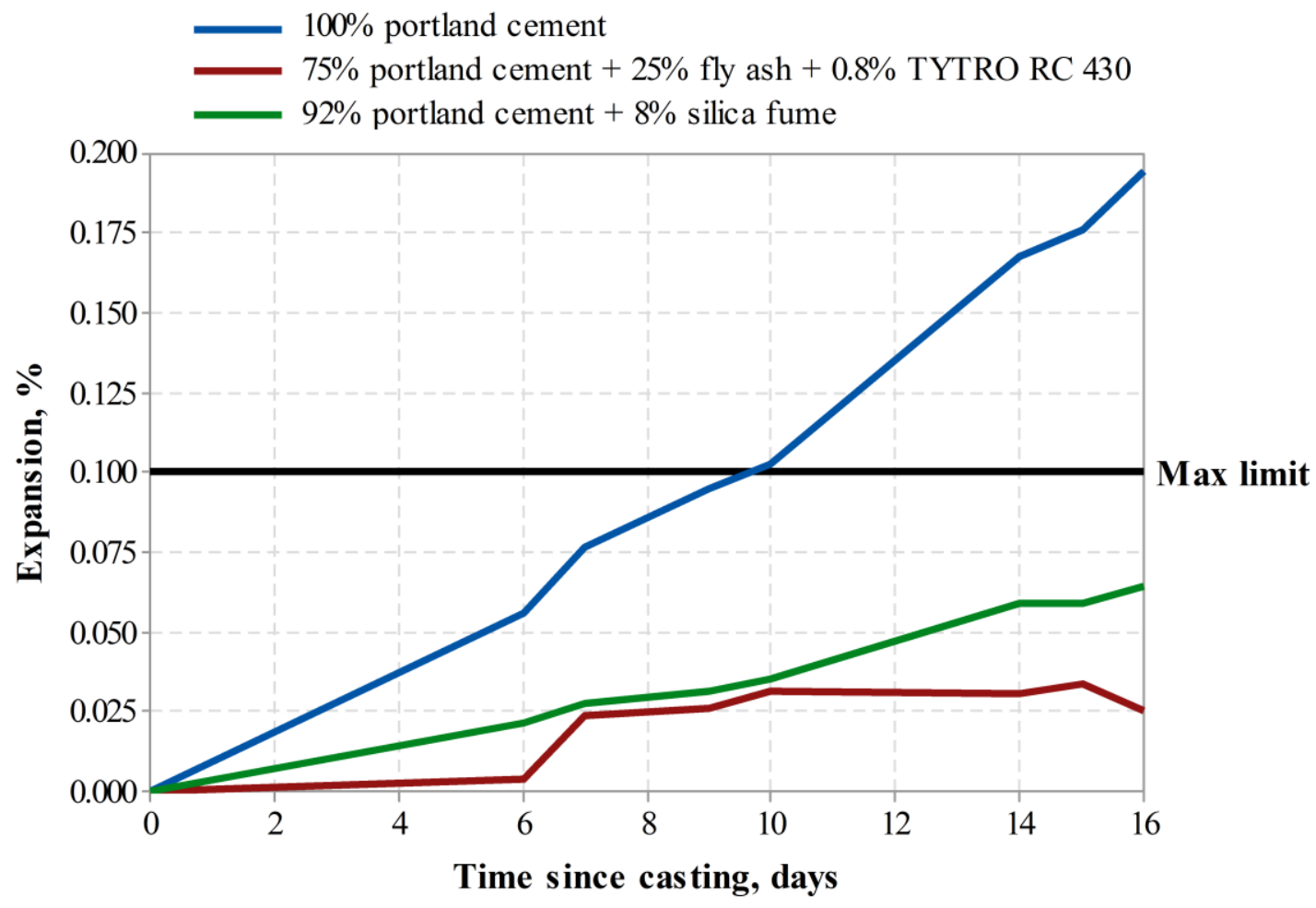

Figure 1 Accelerated mortar bar testing to evaluate ASR potential

This finding also confirms the literature (Shafaatian et al. 2013; Malvar \& Lenke 2005; Shehata \& Thomas 2000 ) that fly ash is capable of controlling ASR in concrete at moderate levels of replacement (20 to $30 \%$ ) due to the following three mechanisms (Detwiler 1997):

- Dilution of the cement alkalis by mixing the cement with fly ash with a lower alkali content.

- Removal of some of the alkalis from the pore solution by binding into the low lime/silica ratio hydration products, thus, lowering the $\mathrm{OH}$-concentration of the pore solution and reducing their availability to the reactive aggregate.

- Pozzolanic reaction of fly ash fills in the pores and reduces their connectivity, thus, reducing the permeability to water and the diffusivity to alkalis supplied by external sources.

\subsubsection{Air content prior to shooting}

Shotcrete mixes are deliberately batched with high initial air content compared to conventional concrete because high air content increases the paste volume, which in turn improves the pumpability of the mix (Beaupré 1994). However, these high initial air contents are temporary because, during pumping and spraying, a large portion of the entrained and entrapped air is often lost due to the compaction process (Jolin \& Beaupré 2003). As a result, the ultimate air content of the sprayed mix is often reduced enough to meet the target air content while avoiding the detrimental effect of high air content on compressive strength. Therefore, in this project, the target air content before shooting was specified to range between 4 and $8 \%$. As shown in Figure 2, both mixes were within the target range. 


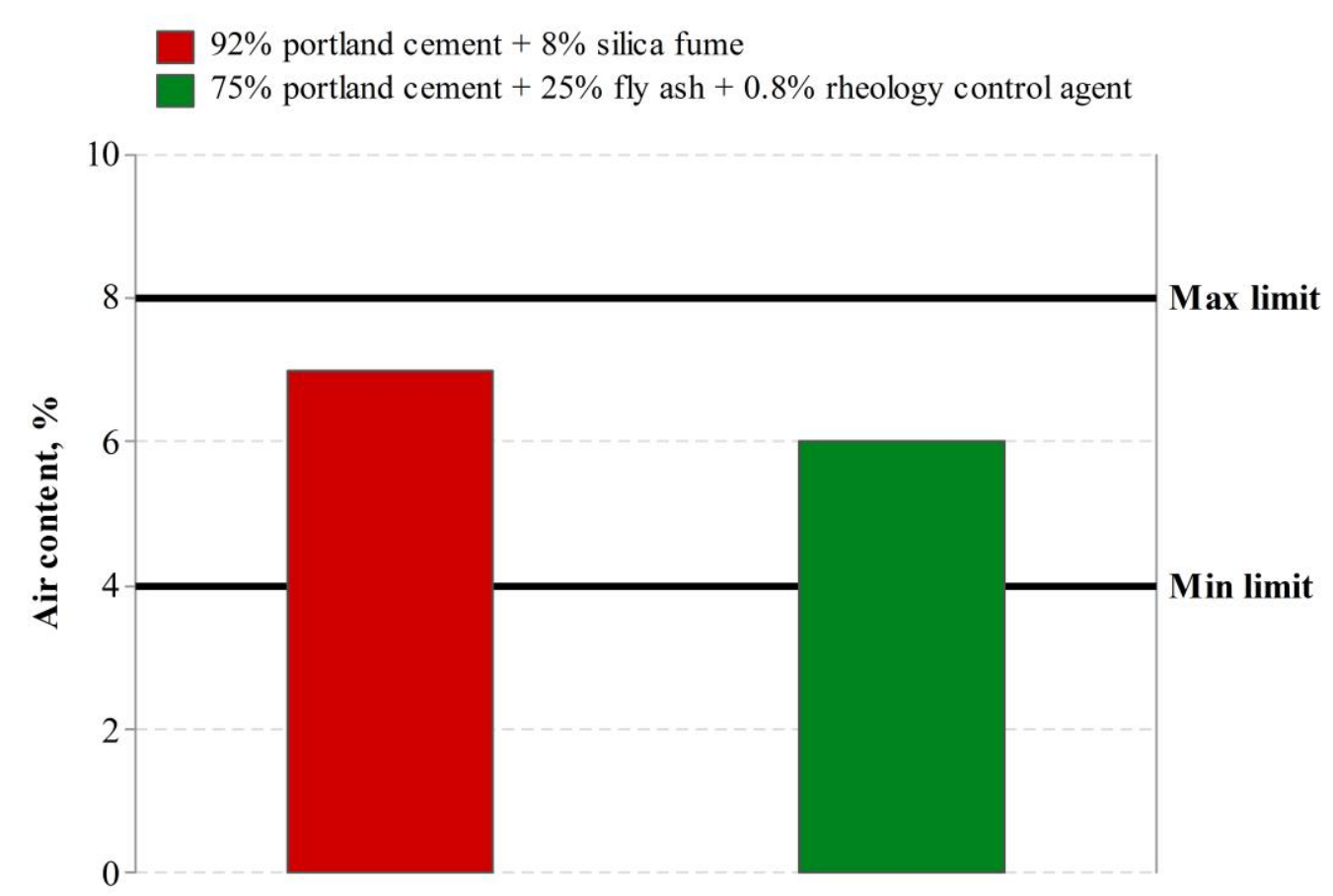

Figure 2 Comparison of air content prior to shooting

\subsubsection{Slump}

Slump was specified to range between 160 to $220 \mathrm{~mm}$. According to Figure 3, both mixes met the slump requirement. It was significant that the proposed mix containing $0.8 \%$ pozzolanic-based rheology control agent and $25 \%$ fly ash did not require any additional superplasticizers to match the slump of the reference mix despite having $35 \mathrm{~kg} / \mathrm{m}^{3}$ of less binder content, which is expected to reduce slump. Such improvement is most likely due to the spherical particle shape of fly ash lubricating the mix and requiring lower water demand than the mix containing silica fume.

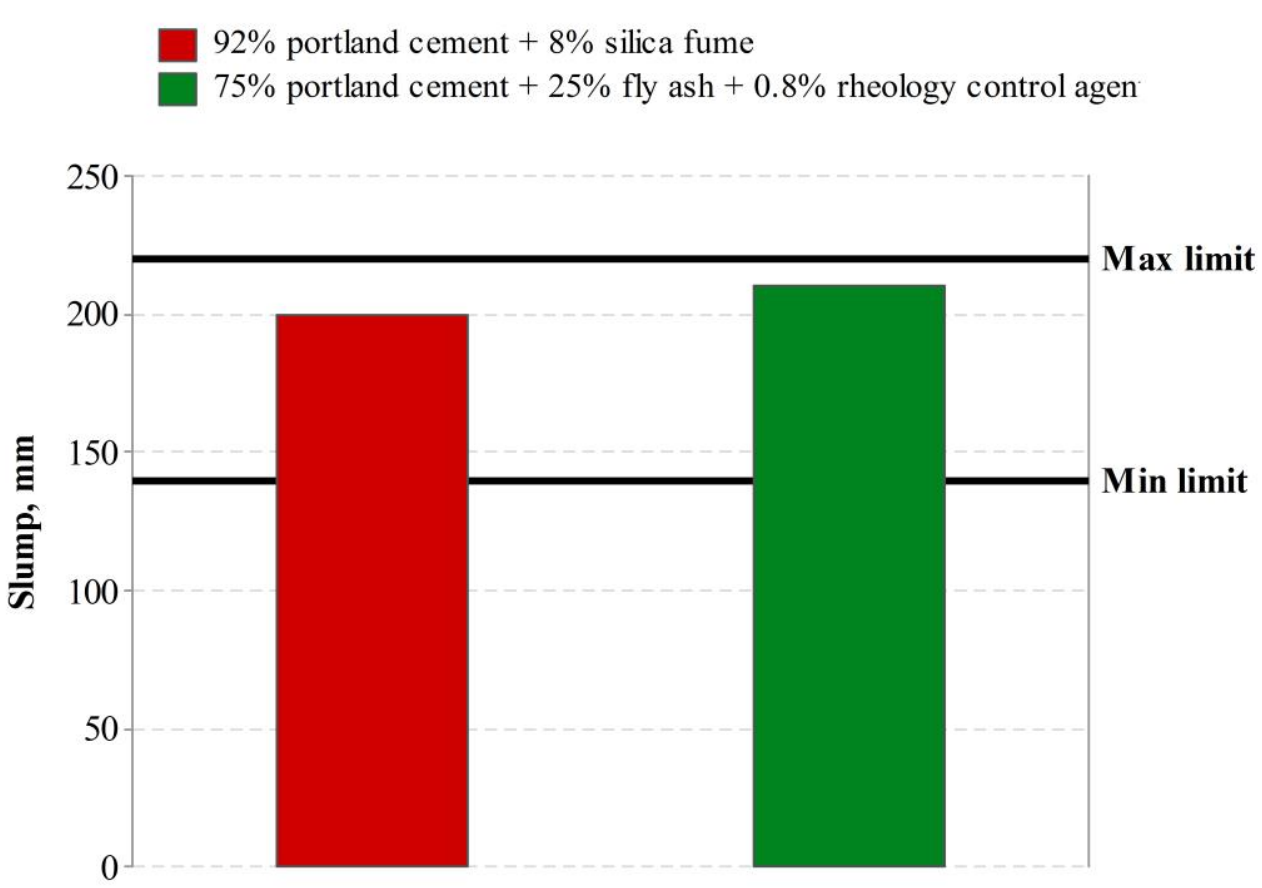

Figure 3 Slump comparison between the reference and proposed mix 


\subsubsection{Strength development at early ages}

The compressive strength at early ages was not specified. However, considering the importance of having high early strength in reducing the re-entry time and supporting the underground structures as fast as possible for increased safety, early strength was evaluated where both the reference and proposed mixes contain $6 \%$ TYTRO $^{\circledR}$ SA 530 shotcrete accelerator. The ambient temperature was $23^{\circ} \mathrm{C}$ at the time of testing both mixes.

As shown in Figure 4, the proposed mix with $25 \%$ fly ash and $0.8 \%$ pozzolanic-based rheology control agent outperformed the mix containing silica fume at all ages. This was quite outstanding because it is well published in the literature (Babu \& Rao 1994; Lane \& Best 1982; Wild et al. 1995) that fly ash significantly reduces early-age strength development due to its slow pozzolanic reaction that does not progress to any significant degree until several weeks after the start of hydration, whereas, silica fume is known to be highly reactive and is expected to have very high-early strength.

$92 \%$ portland cement $+8 \%$ silica fume

$75 \%$ portland cement $+25 \%$ fly ash $+0.8 \%$ rheology control agent

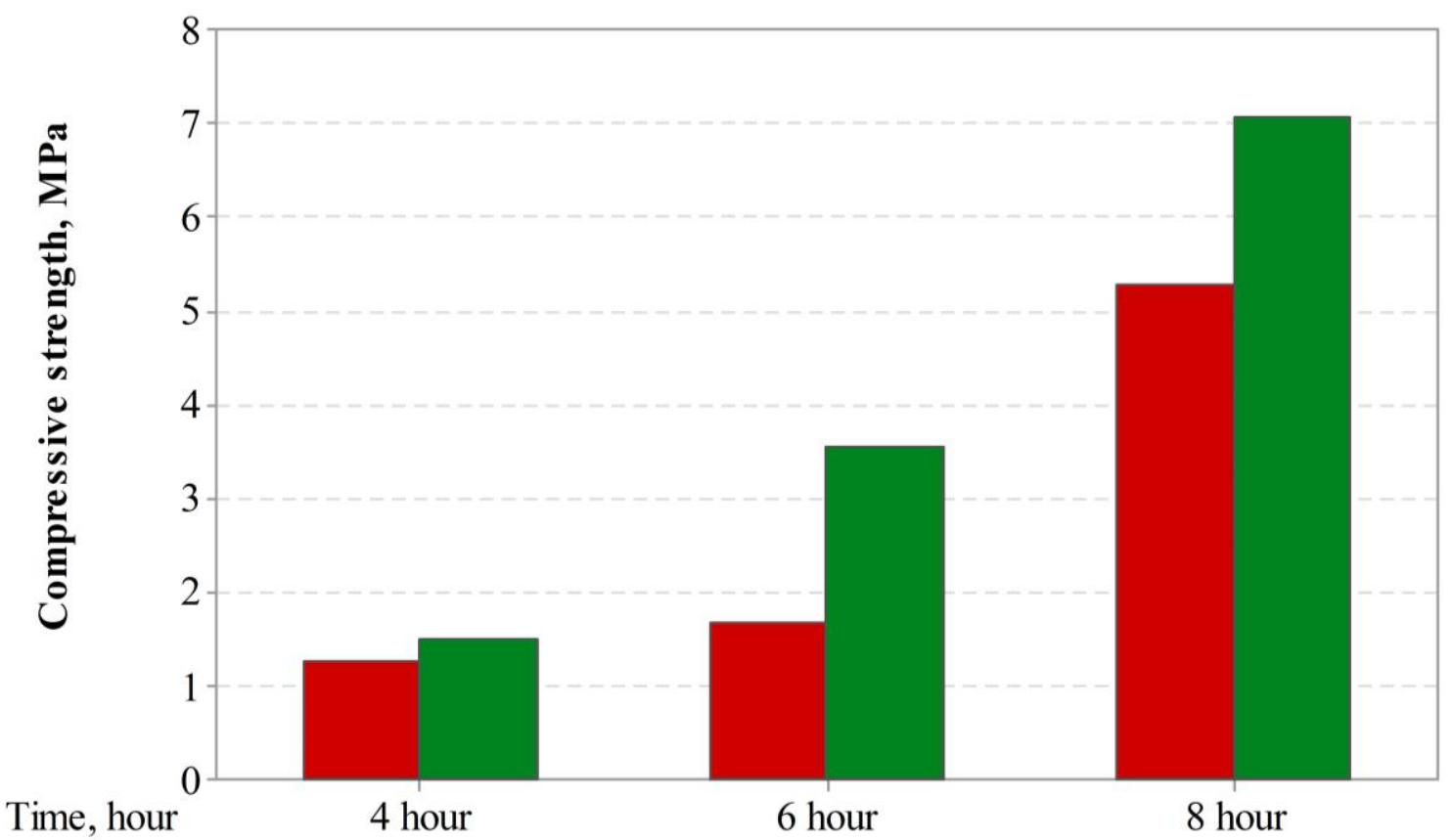

Figure 4 Comparison of compressive strength at early ages

Furthermore, the reference mix containing silica fume had $35 \mathrm{~kg} / \mathrm{m}^{3}$ higher binder content than the proposed mix. The strength reduction expected by the presence of fly ash and reduced binder content was compensated by pozzolanic-based rheology control agent as a result of the following mechanisms:

- TYTRO $^{\circledR}$ RC 430 has much finer particle size (nano-scale) and higher specific surface area than silica fume and fly ash, which increases its pozzolanic reactivity.

- $\mathrm{TYTRO}^{\circledR} \mathrm{RC} 430$ reacts with the calcium hydroxide released by the cement hydration and forming additional calcium silicate hydrate (CSH) gel, which contributes to the strength development.

- TYTRO $^{\circledR}$ RC 430 serves as nucleation sites to CSH gel and accelerates the primary CSH gel formation.

\subsubsection{Compressive strength}

Figure 5 shows the comparison of the compressive strength test results between the reference and proposed mix. Although both mixes had higher strength than the project limits, the proposed mix outperformed the reference mix due to the presence of the pozzolanic-based rheology control agent. 


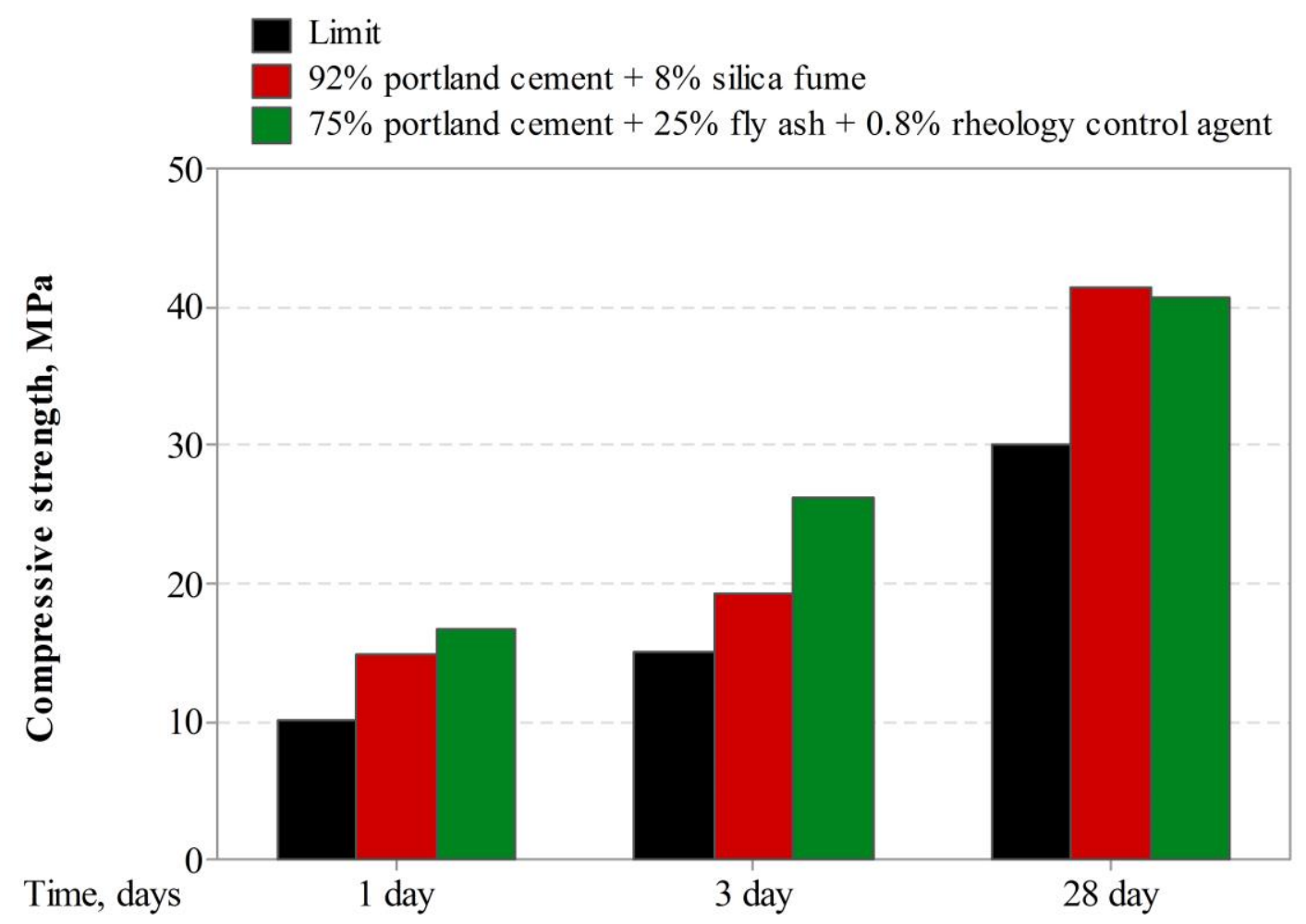

Figure 5 Comparison of compressive strength

The early-age and later-age strength trends show that the impact of pozzolanic-based rheology control agent on compressive strength is more prominent at early ages, and most importantly, unlike other rapid setting materials, it does not harm the later-age strength. This behaviour makes the pozzolanic-based rheology control agent ideal for shotcrete used for ground support where minimal time to re-entry to the mine is desired.

\subsubsection{Flexural toughness}

Table 3 shows the flexural toughness performance of the reference and proposed mixes at seven days, which were tested in accordance with ASTM C1609/C1609M (ASTM International 2012) using three beams per mix with the size of $100 \times 100 \times 350 \mathrm{~mm}$, and evaluated based on the guidelines provided by Morgan et al. (1995). The dosage rate of $6 \mathrm{~kg} / \mathrm{m}^{3}$ of macro-synthetic fibres were used in both mixes. Since the flexural toughness is mainly driven by the fibre quality and dosage rate, which was kept constant in both mixes, they successfully passed the project requirement and exhibited Level III performance.

Table 3 Toughness performance of the proposed mix

\begin{tabular}{llll}
\hline Tested property & $\begin{array}{l}\text { Project } \\
\text { requirement } \\
\text { for Level III }\end{array}$ & $\begin{array}{l}\text { Reference } \\
\text { mix }\end{array}$ & $\begin{array}{l}\text { Proposed } \\
\text { mix }\end{array}$ \\
\hline Flexural strength, MPa & 3.0 & 5.4 & 5.6 \\
\hline Toughness at $0.5 \mathrm{~mm}$ deflection, MPa & 2.0 & 2.0 & 2.1 \\
\hline Toughness at $2.0 \mathrm{~mm}$ deflection, MPa & 1.2 & 1.6 & 1.8 \\
\hline
\end{tabular}




\subsubsection{Durability}

Boiled absorption and volume of permeable voids were specified to evaluate the durability characteristics of the tested mixes at seven days. According to Figure 6, both the reference and proposed mixes performed similar and results were within the specified maximum limit of $8 \%$ boiled absorption and $17 \%$ volume of permeable voids.

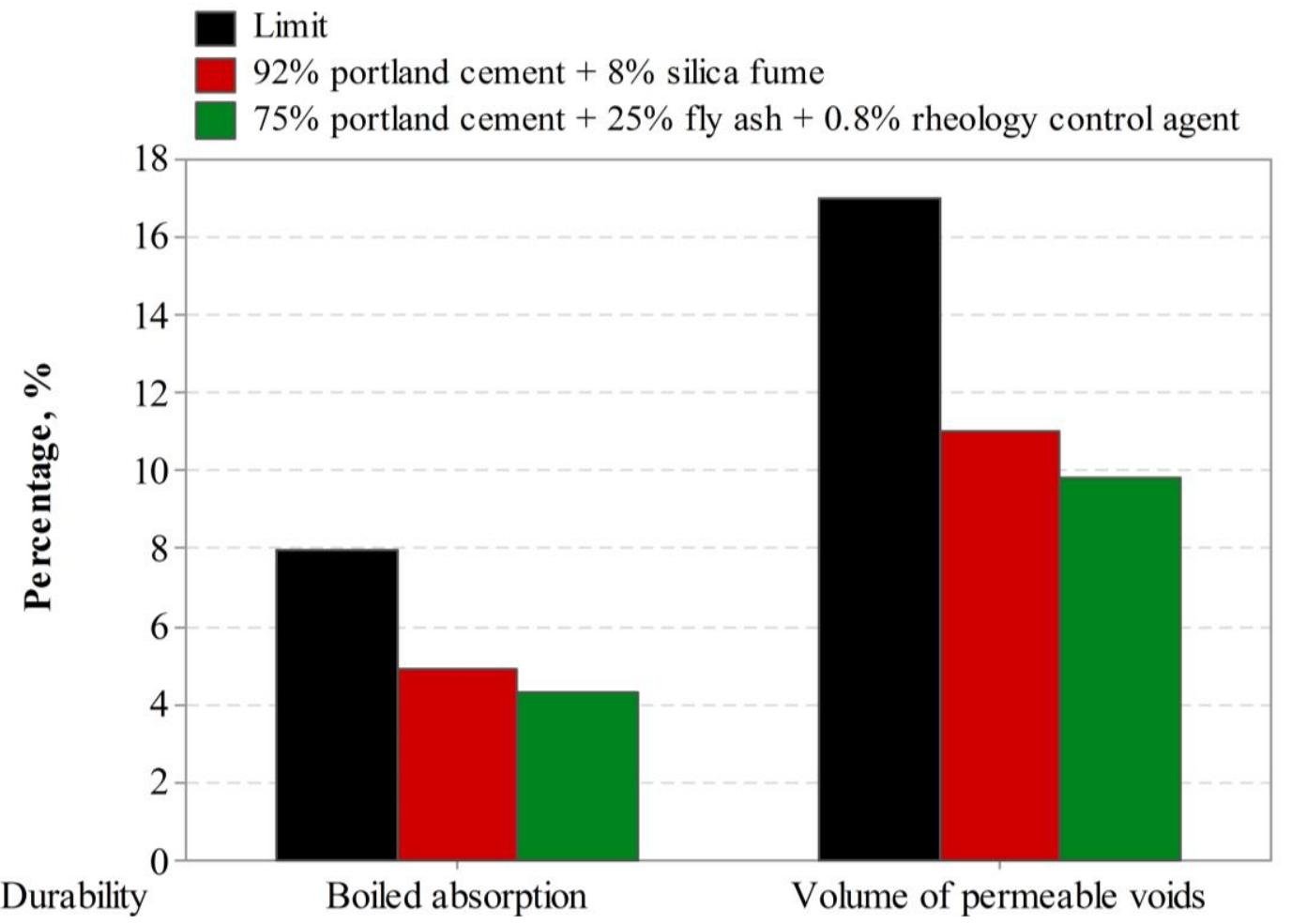

Figure 6 Comparison of boiled absorption and volume of permeable voids between the refence and proposed mixes

\subsection{Phase 2 - field trials}

After confirming the suitability of the proposed mix design to meet the project limits under laboratory conditions, trials were conducted at actual jobsite to validate the field performance.

\subsubsection{Fresh properties}

The proposed mix containing $25 \%$ fly ash and $0.8 \%$ pozzolanic-based rheology control agent was batched and tested, both at the ready-mix concrete plant and jobsite. Target slump at the jobsite, prior to discharge, was $180 \pm 40 \mathrm{~mm}$, and air content was specified to range between 4 and $8 \%$, as listed in Table 3. Mix met the project specifications as slump was obtained as $210 \mathrm{~mm}$ and air content was $4.7 \%$.

\subsubsection{Hardened properties}

After getting the confirmation that the mix met the required fresh properties, the proposed mix was sprayed using a robotic arm both towards perpendicular and overhead panels to evaluate the sprayability. Due to the presence of pozzolanic-based rheology control agent, mix was very cohesive and sticky, which exhibited very good placeability with little rebound (visually assessed). During the spraying process, shotcrete accelerator was used at $6 \%$ dosage rate (by weight of binder content). Cores and beams were taken to perform compressive strength and toughness testing. According to the test results, mix obtained $22 \mathrm{MPa}$ of compressive strength at seven days and met the Level III toughness performance (toughness level was evaluated based on Morgan et al. 1995). 


\section{Conclusion}

Based on the obtained test results, the following conclusions are drawn:

- Pozzolanic-based rheology control agent can be used as a replacement to silica fume, and it is compatible to be used along with other SCMs such as fly ash or slag cement.

- Incorporating pozzolanic-based rheology control agent was able to reduce the binder content by $35 \mathrm{~kg} / \mathrm{m}^{3}$ but still provided equivalent performance.

- The combination of fly ash and pozzolanic-based rheology control agent is effective to control ASR at the selected dosage rates and, more importantly, the negative impact of fly ash on early-age strength is compensated with the presence of a pozzolanic-based rheology control agent.

- With the use of full TYTRO ${ }^{\circledR}$ system, all the requirements listed in this major ground support project are met while providing a cost-effective solution.

\section{References}

ASTM International 2013, ASTM C1567 Standard test method for determining the potential alkali-silica reactivity of combinations of cementitious materials and aggregate (accelerated mortar-bar method), ASTM International, West Conshohocken, Pennsylvania.

ASTM International 2012, C1609/C1609M Standard test method for flexural performance of fiber-reinforced concrete (using beam with third-point loading), ASTM International, West Conshohocken, Pennsylvania.

Babu, KG \& Rao, GSN 1994, 'Early strength behaviour of fly ash concretes', Cement and Concrete Research, vol. 24, no. 2, pp. $277-284$.

Beaupré, D 1994, 'Rheology of high performance shotcrete', PhD thesis, University of British Columbia, pp. 250.

Bergna, HE \& Roberts, WO 2006, Colloidal silica fundamentals and applications, Taylor and Francis Group, LLC, Boca Raton.

Chiu, YC \& Olek, J 2014, 'Using modified mortar-bar test method to access the effects of deicers on expansion of mortars with and without reactive aggregates', 4th International Conference on the Durability of Concrete Structures, West Lafayette, Indiana.

Degirmenci, N, Yilmaz, A \& Cakir, A 2011, 'Utilization of waste glass as sand replacement in cement mortar', Indian Journal of Engineering \& Materials Sciences, vol. 18, pp. 303-308.

Detwiler, R 1997, 'The role of fly ash composition in reducing alkali-silica reaction', PCA R\&D serial no. 2092, Portland Cement Association.

Garcia-Diaz, E, Riche, J, Bulteel, D \& Vernet, C 2006, 'Mechanism of damage for the alkali-silica reaction', Cement and Concrete Research, vol. 36, pp. 395-400.

Glasser, DLS \& Kataoka, N 1981, 'The chemistry of alkali-aggregate reaction', Cement and Concrete Research, vol. 11, no. 1, pp. 1-9.

Jolin, M \& Beaupré, D 2003, 'Understanding wet-mix shotcrete: mix design, specifications, and placement', Shotcrete Magazine, no. Summer, pp. 6-12.

Lane, RO \& Best, JF 1982, 'Properties and use of fly ash in Portland cement concrete', Concrete International, vol. 4, no. 7, pp. 81-92.

Malvar, LJ \& Lenke, LR 2005, 'Minimum fly ash cement replacement to mitigate alkali silica reaction', 2005 World of Coal Ash (WOCA), Lexington, Kentucky.

Morgan, DR, Mindess, S \& Chen, L 1995, 'Testing and specifying toughness for fibre reinforced concrete and shotcrete', in N Banthia \& S Mindess (eds), Proceedings of the 2nd University-Industry Workshop on Fiber Reinforced Concrete and Other Advanced Composites, Toronto, pp. 29-50.

Ovstaas, G, Heere, R, Horth, R \& Yurdakul, E 2015, 'Evaluation of the use of colloidal silica as a silica fume replacement in wet mix shotcrete', in Proceedings of the 5th International Conference on Construction Materials: Performance, Innovations and Structural Implications, Whistler.

Poyet, S, Sellier, A, Capra, B, Foray, G, Torrenti, JM, Cognon, H \& Bourdarot, E 2007, 'Chemical modelling of alkali silica reaction: Influence of the reactive aggregate size distribution', Materials and Structures, vol. 40, no. 2, pp. 229-239.

Shafaatian, SMH, Akhavan, A, Maraghechi, H \& Rajabipour, F 2013, 'How does fly ash mitigate alkali-silica reaction (ASR) in accelerated mortar bar test (ASTM C1567)?', Cement \& Concrete Composites, vol. 37, pp. 143-153.

Shehata, MH \& Thomas, MDA 2000, 'The effect of fly ash composition on the expansion of concrete due to alkali-silica reaction', Cement and Concrete Research, vol. 30, pp. 1063-1072.

Wild, S, Sabir, BB \& Khatib, JM 1995, 'Factors influencing strength development of concrete containing silica fume', Cement and Concrete Research, vol. 25, no. 7, pp. 1567-1580.

Yurdakul, E \& Rieder, KA 2015, 'Effect of pozzolanic based rheology control agent as a replacement for silica fume on wet-mix shotcrete performance', Shotcrete Magazine, no. Spring, pp. 26-31. 
